Check for updates

Cite this: RSC Adv., 2018, 8, 37146

Received 4th September 2018 Accepted 29th October 2018

DOI: $10.1039 / c 8 r a 07389 a$

rsc.li/rsc-advances

\section{CulnS $_{2}-\ln _{2} \mathrm{Se}_{3}$ quantum dots - a novel material via a green synthesis approach $\dagger$}

\begin{abstract}
N. J. Simi, (D) ${ }^{a}$ Libin Kuriakose, (D) ${ }^{a}$ R. Vinayakan ${ }^{b}$ and V. V. Ison (D)*a
Novel CulnS $S_{2}-\ln _{2} \mathrm{Se}_{3}$ QDs were prepared by a two stage organometallic colloidal synthesis procedure. A layer of indium selenide was grown over the CulnS $S_{2}$ QD core, under high temperature in the presence of oleylamine. The optical properties of the nanostructures grown were studied using UV-Vis absorption spectroscopy and the band gap obtained was in line with the cyclic voltammetry (CV) results. The elemental composition was analysed using energy dispersive $\mathrm{X}$-ray spectroscopy (EDAX), inductive coupled plasma-atomic emission spectroscopy (ICP-AES) and X-ray photoelectron spectroscopy (XPS). The structural properties were investigated using $X$-ray diffraction (XRD) and high resolution transmission electron microscopy (HRTEM). The TEM images showed spherical nanostructures of size about $4.8 \mathrm{~nm}$ with well-defined lattice planes which were also evident from selected area electron diffraction (SAED) patterns. The XRD pattern indicated a tetragonal chalcopyrite crystal structure for the nanostructures.
\end{abstract}

\section{Introduction}

Engineering the physical and chemical properties of semiconductor nanostructures or quantum dots (QDs) has been a frontier research area for the past three decades. ${ }^{1-5}$ The efficaciousness of QDs lies in controlling their properties by tuning the size, shape and composition..$^{6-9}$ In addition, the choice of an organic surfactant layer protecting the nanostructure expands the possibility of surface engineering. ${ }^{\mathbf{1 0 , 1 1}}$ Though cadmium and lead based nanoparticles are verified with high applicability, ${ }^{\mathbf{1 2 , 1 3}}$ their inherent toxicity calls forth environment friendly and commercially viable 'green' nanostructures, ${ }^{13-15}$ particularly when biomedical applications are concerned. ${ }^{16,17}$ Green QDS include I-III-VI 2 compounds such as $\mathrm{CuInS}_{2}$ (CIS), $\mathrm{CuInSe}_{2}$ (CISe), and CuInSeS (CISeS) along with many other binary quantum dots which are free from heavy metals. ${ }^{18,19}$ Among these, CIS and CISe are direct band gap semiconductors with band gap onset in the NIR region. ${ }^{\mathbf{2 0 , 2 1}}$ Besides, the high absorption coefficient makes them efficient in light harvesting applications. ${ }^{22}$ But, compared to the binary II-VI QDs, the slow hole scavenging and the presence of surface trap states limits the use of these I-III- $\mathrm{VI}_{2}$ nanostructures in different applications. This is due to the non-stoichiometric compositions and complex crystal structures of these nanostructures. ${ }^{23,24} \mathrm{~A}$ possible solution to overcome these issues is to passivate the surface states by an epitaxial growth of a semiconductor layer

${ }^{a}$ Centre for Nano Bio Polymer Science and Technology, Department of Physics, St. Thomas College, Palai, Arunapuram, Kottayam-686574, Kerala, India. E-mail: isonv@rediffmail.com; Tel: +919446126926

${ }^{b}$ NSS Hindu College, Changanacherry, Kottayam-686102, Kerala, India

$\dagger$ Electronic supplementary information (ESI) available. See DOI: 10.1039/c8ra07389a which further modifies the electronic properties of the nanostructures synthesized. ${ }^{24-27}$ Recently, Kim et al. observed that a $\mathrm{ZnS}$ shell over CISe core reduced non-radiative recombination and interfacial electron recombination in them. ${ }^{15}$ Similarly, Donega and coworkers reported an appreciable improvement in photoluminescence quantum yield of CIS QDs by over coating with ZnS or CdS. ${ }^{28,29}$ The same observation was also reported by Klimov and coworkers while evaluating light emission mechanisms in a CIS/ZnS core-shell system..$^{30}$ Most of the reported works on CIS and CISe QDs are based on growing a ZnS passivating layer over the core to form a core/shell type-I structure. ${ }^{17,31-33}$ In some earlier attempts, $\operatorname{In}_{2} \mathrm{~S}_{3}$ was used in conjunction with CIS thin films for improving the performance of thin film based photovoltaic systems. ${ }^{34,35}$ Also, $\mathrm{In}_{2} \mathrm{Se}_{3}$ has been employed as a buffer layer in devising CIS QD sensitized solar cells. ${ }^{36}$ In the present study, the effort is to grow an indium selenide $\left(\mathrm{In}_{2} \mathrm{Se}_{3}\right)$ passivating layer over the CIS core, which not only acts as a surface passivating layer, but also results in a typeII band offset, which can confine the holes in the core and the electrons in the outer layer ${ }^{37}$ (Scheme 1). The resulting charge

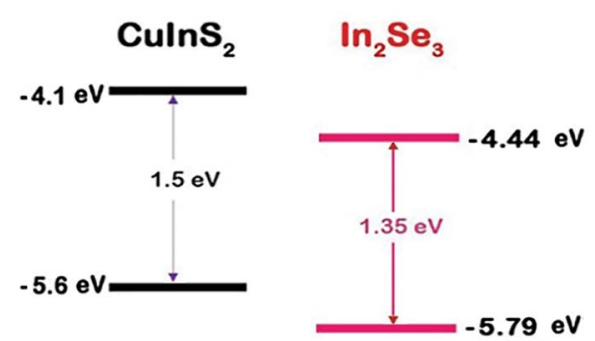

Scheme 1 Schematic representation of the energy level diagrams of $\mathrm{CIS}$ and $\mathrm{In}_{2} \mathrm{Se}_{3}$. 
separation makes the material ideal for photovoltaic applications. Besides, since the lattice mismatch is less, $\operatorname{In}_{2} \mathrm{Se}_{3}$ is a suitable choice as a passivating layer for CIS. ${ }^{38}$ To the best of our knowledge, CIS QDs with $\mathrm{In}_{2} \mathrm{Se}_{3}$ as a passivating layer is not yet reported. Also, in the present study, we are adopting a phosphine free, 'green route' for the synthesis. ${ }^{18,39,40}$ The advantage of the colloidal method lies in its control of particle size and shape distribution with less number of defect

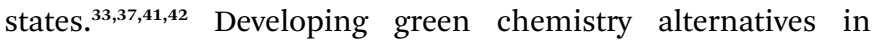
nanomaterials synthesis is a major concern of the research community. ${ }^{43}$ In our synthesis, to avoid the toxicity caused by the organophosphines, we dissolved the elemental selenium in the capping agent-coordinating solvent (oleylamine-octadecene) mixture. To grow a layer of $\mathrm{In}_{2} \mathrm{Se}_{3}$, the selenium coordinated to oleylamine was injected to the CIS QD dispersion. A similar type of shell growth strategy was reported from Zhong group, except that the exchange was of cations. ${ }^{22}$

\section{Experimental section}

\section{Materials}

Copper(I) iodide (CuI, Puratronic, 99.998\%), indium(III) acetate $\left(\mathrm{In}(\mathrm{OAc})_{3}, 99.99 \%\right)$ were purchased from Alfa Aesar. Sulfur powder (S, 99.99\%), selenium powder (Se, 200 mesh, 99.99\%), oleylamine (OAm, 97\%) and 1-octadecene (ODE, 90\%) were purchased from Sigma-Aldrich. The chemicals were used as procured without further purification.

\section{Characterisation}

The FTIR spectrum was recorded using Perkin Elmer spectrum 400 spectrometer. The absorption spectra were recorded using a Shimadzu-3600 UV-VIS-NIR spectrophotometer. The high resolution transmission electron microscopic images of the QDs were recorded using JEOL $200 \mathrm{kV}$ JEM-2100 microscope, after depositing them on carbon coated copper grids. The elemental composition was analysed with X-ray photoelectron spectroscopy (PHI 5000 Versa Probe II X-ray photoelectron spectrometer using $\mathrm{Mg} \mathrm{K} \alpha$ radiation), inductive coupled plasma-atomic emission spectroscopy (Perkin Elmer Optima $5300 \mathrm{DV}$ ) and energy dispersive X-ray spectroscopy (JED-2300 analysis station). The crystal structure was studied using selected area electron diffraction pattern and X-ray diffraction analysis (Rigaku miniplex X-ray diffractometer using $\mathrm{Cu} \mathrm{K} \alpha$ radiation). The electrochemical bandgap of the material was determined from cyclic voltammograms recorded using an Autolab 204N electrochemical workstation (Metrohm Autolab) employing a three electrode configuration with a scan rate of $50 \mathrm{mV} \mathrm{s}^{-1}$. In the instrument, glassy carbon was used as the working electrode, platinum wire as the auxiliary electrode and silver/silver chloride electrode as the reference electrode. Also, tetrabutyl ammonium hexafluorophosphate $(0.1 \mathrm{M})$ was used as the supporting electrolyte.

\section{Synthesis of $\mathrm{CuInS}_{2}$ QDs}

Oleylamine capped CIS QDs were prepared by following a reported procedure. ${ }^{22}$ In brief, a mixture of $\mathrm{CuI}(0.038 \mathrm{~g}, 0.2$ $\mathrm{mmol}), \mathrm{In}(\mathrm{OAc})_{3}(0.058 \mathrm{~g}, 0.2 \mathrm{mmol}), \mathrm{OAm}(6 \mathrm{ml}, 0.018 \mathrm{mmol})$ and 1-ODE $(12 \mathrm{ml})$ were heated to $180{ }^{\circ} \mathrm{C}$, in a three necked round bottom flask under argon atmosphere with continuous stirring until a clear pale yellow solution was obtained. At this temperature, an injection mixture containing sulphur $(0.0192 \mathrm{~g}$, $0.6 \mathrm{mmol})$ in OAm $(0.6 \mathrm{ml}, 0.0018 \mathrm{mmol})$ was injected into the reaction mixture and kept for 20 minutes. The OAm capped CIS QDs obtained were purified by precipitation with acetone and dispersed in chloroform.

\section{Synthesis of $\mathrm{CuInS}_{2}-\mathrm{In}_{2} \mathrm{Se}_{3}$ QDS}

To grow a thin layer of $\operatorname{In}_{2} \mathrm{Se}_{3}$ over the CIS QDs prepared, the dots were loaded in a round bottom flask along with $6 \mathrm{ml} \mathrm{OAm}$ and $12 \mathrm{ml} \mathrm{ODE}$ and heated to $40{ }^{\circ} \mathrm{C}$ under vacuum for 20 minutes. The vacuum was then replaced with argon and the reaction mixture was further heated to $170{ }^{\circ} \mathrm{C}$, under constant stirring. At this temperature, $0.3 \mathrm{ml}$ Se solution $(0.078 \mathrm{~g}$ Se powder dissolved in a mixture of $1 \mathrm{ml}$ OAm and $2 \mathrm{ml}$ ODE) was injected into it and kept for $30 \mathrm{~min}$ for the growth of the $\mathrm{In}_{2} \mathrm{Se}_{3}$ layer over the CIS QDs. The CIS- $\mathrm{In}_{2} \mathrm{Se}_{3}$ QDs obtained were purified by precipitation with methanol twice and then with acetone. The nanostructures obtained were dispersed in chloroform for further studies.

\section{Results and discussion}

CIS- $\mathrm{In}_{2} \mathrm{Se}_{3}$ QDs obtained were stable and the OAm capping agent rendered them were easily dispersible is non polar organic solvents. The presence of OAm attached to the QD surface was evaluated by FTIR studies (Fig. S1 $\dagger$ ). The absorption spectra obtained for CIS- $\mathrm{In}_{2} \mathrm{Se}_{3}$ of different CIS QD core sizes is shown in Fig. 1. The figure shows that the over coating of CIS with $\mathrm{In}_{2} \mathrm{Se}_{3}$ results in a red shift in the absorption spectra, compared to that of the CIS core (Fig. S2 $\dagger$ ). The further extension of the absorption onset to the NIR region makes the material more suitable as a light harvester in photovoltaic applications. The band gap energy $\left(E_{\mathrm{g}}\right)$ of CIS and CIS- $\mathrm{In}_{2} \mathrm{Se}_{3}$ QDs were determined as 1.91 and $1.81 \mathrm{eV}$ respectively, by Tauc plot (Fig. S3 $\dagger$ ), using the relation $\alpha=\beta /(h \nu)\left(h \nu-E_{\mathrm{g}}\right)^{n}$, where $\alpha$ is

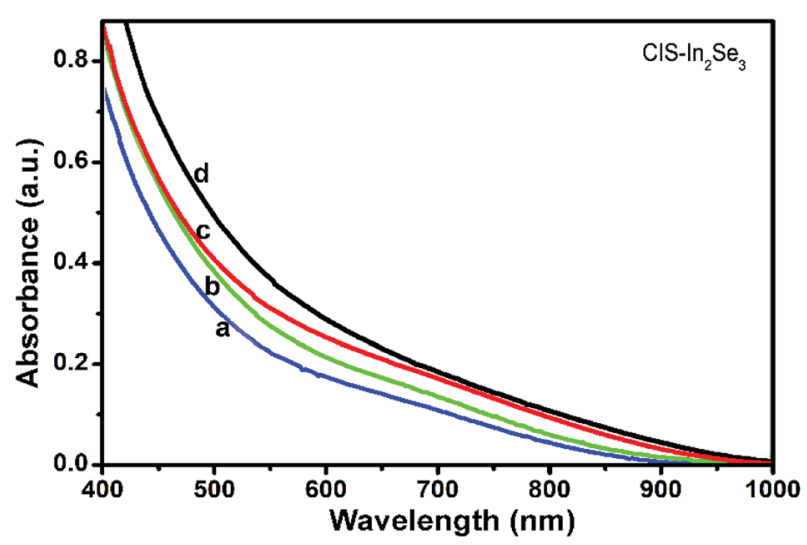

Fig. 1 Absorption spectra of CIS- $\mathrm{In}_{2} \mathrm{Se}_{3}$ QDs in chloroform (a $\rightarrow$ d), with increasing $\mathrm{CIS}$ core sizes. 
the linear absorption coefficient and $\beta$ is the band gap tailoring parameter constant. ${ }^{44-46}$

The luminescence observed in CIS (Fig. S4 $\dagger$ ) has disappeared in CIS- $\mathrm{In}_{2} \mathrm{Se}_{3}$ due to the charge separation, a characteristic of a type-II system. ${ }^{47}$

The HOMO and LUMO levels and the bandgap energy of the materials synthesized were estimated using cyclic voltammetry measurements. The HOMO and LUMO levels were calculated from the onset of oxidation peak $\left(E^{\mathrm{Ox}}\right)$ and reduction peak $\left(E^{\mathrm{Red}}\right)$ using the following equations. ${ }^{39}$

$$
\begin{aligned}
& E_{\mathrm{HOMO}}=-\left[E^{\mathrm{Ox}}+4.7\right] \mathrm{eV} \\
& E_{\mathrm{LUMO}}=-\left[E^{\text {Red }}+4.7\right] \mathrm{eV}
\end{aligned}
$$

From Fig. 2, using the oxidation and reduction peak onsets (1.05 and $-0.82 \mathrm{eV}$ ), the HOMO and LUMO levels of the CIS$\mathrm{In}_{2} \mathrm{Se}_{3}$ QDs were estimated as -5.75 and $-3.88 \mathrm{eV}$ respectively. This gives the band gap as $1.87 \mathrm{eV}$, which is in close agreement with the value obtained from the absorption data. Also, the band gap for CIS was estimated as $1.95 \mathrm{eV}$ (Fig. S5†), which is also in agreement with optical spectral data.

The high resolution transmission electron microscopic (HRTEM) images (Fig. 3) indicated a spherical geometry and a uniform size distribution for the CIS- $\mathrm{In}_{2} \mathrm{Se}_{3}$ QDs. The average grain size was estimated to be around $4.8 \mathrm{~nm}$ with lattice spacing ( $d$ value) $0.33 \mathrm{~nm}$. The $d$ spacing obtained corresponds to the spacing of (112) lattice planes of the tetragonal chalcopyrite structure (ICDD 36-1311). The $d$ value was also measured from the SAED pattern (inset of Fig. 3), which also confirmed the good crystallinity of the QDs.

The elemental composition of the CIS- $\mathrm{In}_{2} \mathrm{Se}_{3}$ QDs was analysed using energy dispersive X-ray analysis (Fig. 4), with the composition ratio $\mathrm{Cu}: \mathrm{In}: \mathrm{S}: \mathrm{Se}$ as $1: 1.1: 0.7: 0.34$. The spectrum confirmed the presence of selenium, in addition to copper, indium and sulphur seen for the CIS QDs (Fig. S6 $\dagger$ ). Presence of selenium in the CIS- $\mathrm{In}_{2} \mathrm{Se}_{3}$ nanostructure was also confirmed by ICP-AES studies (data not shown).

The elemental composition as well as the valence states of CIS- $\mathrm{In}_{2} \mathrm{Se}_{3}$ QDs were analysed by XPS. The resolved spectra,

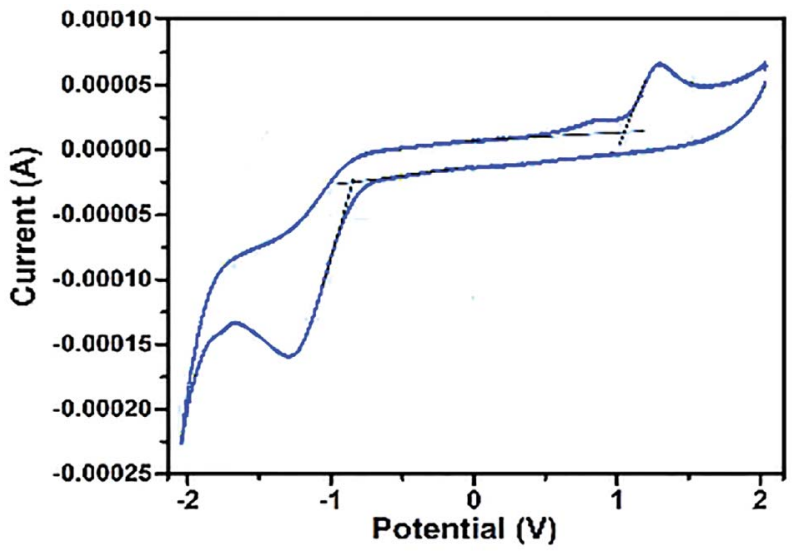

Fig. 2 Cyclic voltammograms of CIS- $\ln _{2} \mathrm{Se}_{3}$ QDs.

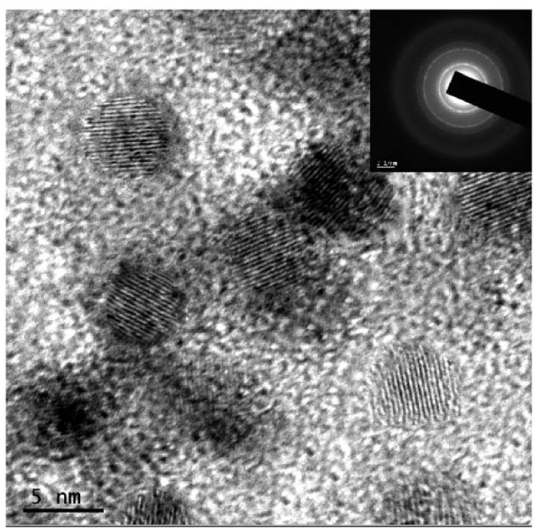

Fig. 3 High resolution TEM image of CIS $-\ln _{2} \mathrm{Se}_{3}$ QDS.

calibrated with C1s as the reference $(284.60 \mathrm{eV})$ is shown in Fig. 5 (combined spectrum is shown in ESI Fig. S7 $\dagger$ ). The $\mathrm{Cu} 2 \mathrm{p}$ core splits into $\mathrm{Cu} 2 \mathrm{p}_{3 / 2}(931.46 \mathrm{eV})$ and $\mathrm{Cu} 2 \mathrm{p}_{1 / 2}(951.38 \mathrm{eV})$ with a peak separation $19.92 \mathrm{eV}$ which is in close agreement with the standard data. ${ }^{48}$ Also, the absence of peak at $942 \mathrm{eV}$ corresponding to the cuprous state, confirms the +2 oxidation state of copper. ${ }^{49}$ Peaks at $443.26 \mathrm{eV}$ and $450.81 \mathrm{eV}$, separated by $7.55 \mathrm{eV}$ in Fig. 5(b) is ascribed to binding energies of In $3 \mathrm{~d}_{5 / 2}$ and In $3 \mathrm{~d}_{3 / 2}$ which assigns a +3 oxidation state to indium. ${ }^{36,50}$ Peaks at 160.4 and $161.6 \mathrm{eV}$, separated by $1.2 \mathrm{eV}$ (Fig. 5(c)), corresponds to sulphur $2 \mathrm{p}_{3 / 2}$ and $2 \mathrm{p}_{1 / 2}$, arising by spin-orbit coupling. This is an also an indication of sulphur bonded with both indium and copper. ${ }^{51}$ The peak at $53.4 \mathrm{eV}$ in Fig. $5(\mathrm{~d})$ is attributed to the binding energy of selenium $3 \mathrm{~d}$. Indium and selenium $3 \mathrm{~d}$ spectral features are in consistence with $\gamma-\mathrm{In}_{2} \mathrm{Se}_{3}$ structural characteristics. ${ }^{36,50,52}$

Crystalline nature of CIS- $\operatorname{In}_{2} \mathrm{Se}_{3}$ QDs was analysed using the X-ray diffraction pattern shown in Fig. 6 (XRD data of CIS QDS are provided in Fig. S8 $\dagger$ ). Three major broad peaks at $26.94^{\circ}$, $46.20^{\circ}$ and $54.93^{\circ}$ correspond to the (112), (220) and (312) planes with lattice constants $a=b=5.552 \AA$ and $c=12.273 \AA$. The data matches well with a tetragonal chalcopyrite crystal structure (ICDD 36-1311). The size of the QDs were estimated as $4.78 \mathrm{~nm}$ from the XRD peaks based Debye's Scherrer formula and was found to be in good agreement with the value obtained from the TEM images.

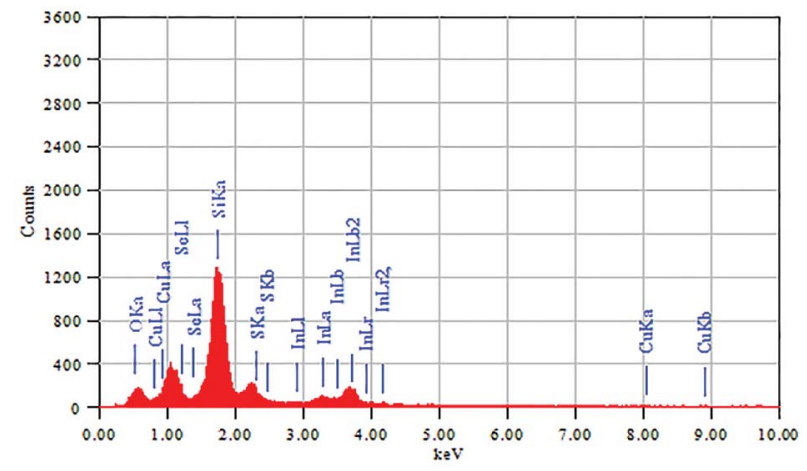

Fig. 4 EDAX spectrum of $\mathrm{CIS}-\mathrm{In}_{2} \mathrm{Se}_{3}$ QDs. 

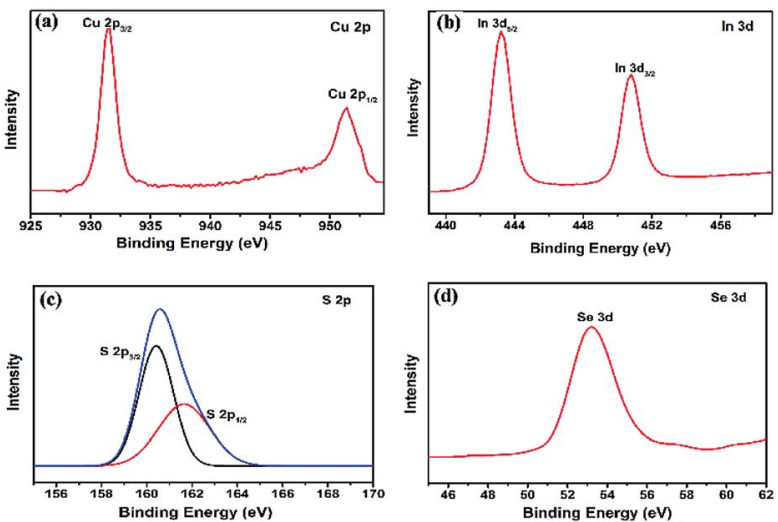

Fig. 5 High resolution XPS spectra of (a) Cu $2 p(b) \ln 3 d$ (c) S $2 p$ and (d) Se 3d.

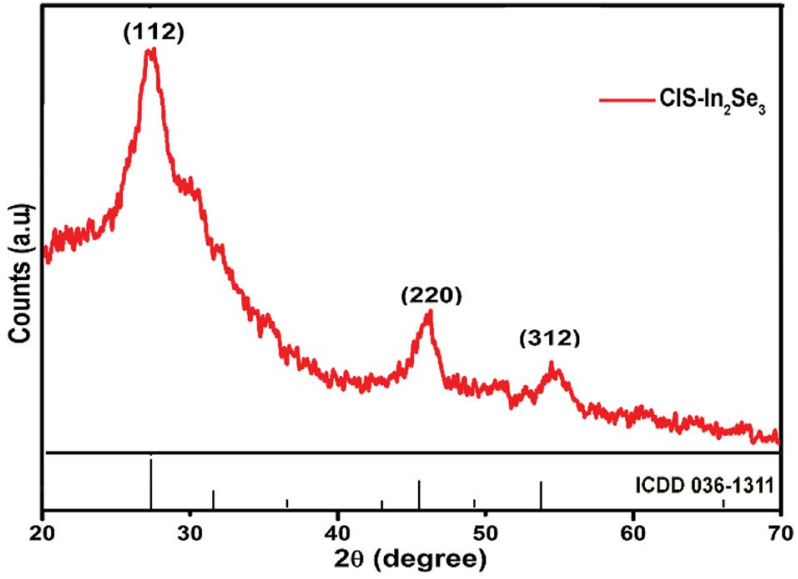

Fig. 6 X-ray diffraction (XRD) pattern of CIS $-\ln _{2} \mathrm{Se}_{3}$ QDs along with standard ICDD reference.

\section{Conclusions}

In summary, a novel material, $\mathrm{CuInS}_{2}-\mathrm{In}_{2} \mathrm{Se}_{3}$ QDs was prepared following a two stage organometallic synthesis route. Low toxic and less expensive oleylamine was used as the ligand to make the synthesis procedure a phosphine free 'green method'. The CIS QD core was prepared first and selenium was then introduced to grow a thin layer of indium selenide over it. The optical absorption properties were found to be superior, covering the entire visible region, extending to the NIR region, making them suitable for photovoltaic applications. The band gap values obtained from absorption data was further confirmed by $\mathrm{CV}$ measurements. The nanostructures were found to be spherical with well-defined lattice planes as evident from the TEM images. The chemical composition was analysed using EDAX, ICP-AES and XPS studies. XRD analysis indicated a tetragonal chalcopyrite structure for the CIS- $\mathrm{In}_{2} \mathrm{Se}_{3}$ QDs. The potential of this material as a light harvester is under further investigations.

\section{Conflicts of interest}

There are no conflicts to declare.

\section{Acknowledgements}

The corresponding author V. V. Ison thank SERB, DST, Govt. of India, for a fast track project (Order No. SR/FTP/PS-108/2010).

\section{References}

1 M. Ye, X. Gao, X. Hong, Q. Liu, C. He, X. Liu and C. Lin, Sustainable Energy Fuels, 2017, 6, 1217-1231.

2 J. Duan, H. Zhang, Q. Tang, B. He and L. Yu, J. Mater. Chem. A, 2015, 17497-17510.

3 A. M. Smith and S. Nie, Acc. Chem. Res., 2010, 43, 190-200.

4 G. I. Maikov, R. Vaxenburg, A. Sashchiuk and E. Lifshitz, ACS Nano, 2010, 4, 6547-6556.

5 S. Mourdikoudis and L. M. Liz-Marzán, Chem. Mater., 2013, 25, 1465-1476.

6 J. Wang, Y. Wang, F. Cao, Y. Guo and L. Wan, J. Am. Chem. Soc., 2010, 132, 12218-12221.

7 P. M. Allen and M. G. Bawendi, J. Am. Chem. Soc., 2008, 130, 9240-9241.

8 S. Rawalekar, S. Kaniyankandy, S. Verma and H. N. Ghosh, J. Phys. Chem. C, 2011, 115, 12335-12342.

9 C. M. Donega, Chem. Soc. Rev., 2011, 40, 1512-1546.

10 L. Liu, X. Guo, Y. Li and X. Zhong, Inorg. Chem., 2010, 49, 3768-3775.

11 B. Bai, D. Kou, W. Zhou, Z. Zhou, Q. Tian, Y. Meng and S. Wu, J. Power Sources, 2016, 318, 35-40.

12 H. Khattak, Journal of Undergraduate Studies at Trent (JUST), 2016, IV, 34-42.

13 H. K. Jun, M. A. Careem and A. K. Arof, Renewable Sustainable Energy Rev., 2013, 22, 148-167.

14 J. Du, Z. Du, J. S. Hu, Z. Pan, Q. Shen, J. Sun, D. Long, H. Dong, L. Sun, X. Zhong and L. J. Wan, J. Am. Chem. Soc., 2016, 138, 4201-4209.

15 J. Kim, J. Yang, J. H. Yu, W. Baek, C. Lee, H. J. Son and K. I. M. E. T. Al, ACS Nano, 2015, 11286-11295.

16 S. Nishimura, A. T. N. Dao, D. Mott, K. Ebitani and S. Maenosono, J. Phys. Chem. C, 2012, 116, 4511-4516.

17 L. Li, T. J. Daou, I. Texier, T. Thi, K. Chi, N. Q. Liem and P. Reiss, Chem. Mater., 2009, 21, 2422-2429.

18 C. A. M. Bonilla and V. V. Kouznetsov, ed. M. L. Larramendy and S. Soloneski, Green Nanotechnology, Overview and Further Prospects, InTech Open limited, London, 2016, pp. 182-201.

19 D. Sharma, R. Jha and S. Kumar, Sol. Energy Mater. Sol. Cells, 2016, 155, 294-322.

20 S. Kim, M. Kang, S. Kim, J. H. Heo, J. H. Noh, S. H. Im, S. II Seok and S. W. Kim, ACS Nano, 2013, 7, 4756-4763.

21 L. Li, A. Pandey, D. J. Werder, B. P. Khanal, J. M. Pietryga and V. I. Klimov, J. Am. Chem. Soc., 2011, 133, 1176-1179.

22 Z. Pan, I. Mora-sero, Q. Shen, H. Zhang, K. Zhao, J. Wang, X. Zhong and J. Bisquert, J. Am. Chem. Soc., 2014, 136, 9203-9210.

23 D. Aldakov, A. Lefrançois and P. Reiss, J. Mater. Chem. C, 2013, 24, 3756-3776.

24 K. Zhao, Z. Pan and X. Zhong, J. Phys. Chem. Lett., 2016, 7, 406-417. 
25 D. Vasudevan, R. R. Gaddam, A. Trinchi and I. Cole, J. Alloys Compd., 2015, 636, 395-404.

26 L. Li, P. Reiss and M. Protie, Small, 2009, 5, 154-168.

27 E. A. Dias, S. L. Sewall and P. Kambhampati, J. Phys. Chem. C, 2007, 111, 708-713.

28 A. C. Berends, F. T. Rabouw, F. C. Spoor, E. Bladt, F. C. Grozema, A. J. Houtepen and C. M. Donega, J. Phys. Chem. Lett., 2016, 7, 3503-3509.

29 C. Xia, D. M. Johannes, C. G. Hans and C. M. Donega, Chem. Mater., 2017, 29, 4940-4951.

30 A. S. Fuhr, H. J. Yun, N. S. Makarov, H. Li, H. McDaniel and V. I. Klimov, ACS Photonics, 2017, 4, 2425-2435.

31 W. Li, Z. Pan and X. Zhong, J. Mater. Chem. A, 2015, 3, 16491655.

32 J. Ma, M. Liu, Z. Li and L. Li, Opt. Mater., 2015, 47, 56-61.

33 C. Xia, J. D. Meeldijk, H. C. Gerritsen and C. M. Donega, Chem. Mater., 2017, 29, 4940-4951.

34 A. S. Cherian, T. Abe, Y. Kashiwaba, C. S. Kartha and K. P. Vijayakumar, Energy Procedia, 2012, 15, 283-290.

35 B. Asenjo, A. M. Chaparro, M. T. Gutierrez, J. Herrero and J. Klaer, Sol. Energy Mater. Sol. Cells, 2005, 87, 647-656.

36 J. Y. Chang, J. M. Lin, L. F. Su and C. F. Chang, ACS Appl. Mater. Interfaces, 2013, 5, 8740-8752.

37 S. Kim, B. Fisher, H. J. Eisler and M. Bawendi, J. Am. Chem. Soc., 2003, 125, 11466-11467.

38 Y. Q. Wang, Y. C. Rui, Q. H. Zhang, Y. G. Li and H. Z. Wang, ACS Appl. Mater. Interfaces, 2013, 5, 11858-11864.
39 S. Cao, W. Ji, J. Zhao, W. Yang, C. Li and J. Zheng, J. Mater. Chem. C, 2016, 4, 581-588.

40 C. Pu, J. Zhou, R. Lai, Y. Niu, W. Nan and X. Peng, Nano Res., 2013, 6, 652-653.

41 E. H. Sargent, Adv. Mater., 2005, 17, 515-522.

42 S. B. Brichkin and V. F. Razumov, Russ. Chem. Rev., 2016, 85, 1297.

43 Y. Pu, F. Cai, D. Wang, J. X. Wang and J. F. Chen, Ind. Eng. Chem. Res., 2018, 57, 1790-1802.

44 P. Taylor, E. A. Davis and N. F. Mott, Philos. Mag., 2006, 22(179), 0903-0922.

45 J. Tauc, Amorphous and Liquid Semiconductor, Plenum Press, New York, 1974.

46 J. Tauc, Mater. Res. Bull., 1968, 3, 37-46.

47 J. E. Halpert, V. J. Porter, J. P. Zimmer and M. G. Bawendi, J. Am. Chem. Soc., 2006, 128, 12590-12591.

48 F. Yuan, B. Chiu, T. Kao, C. Lai and H. Tuan, Energy Environ. Sci., 2011, 4, 4929-4932.

49 H. Zhong, Y. Li, M. Ye, Z. Zhu, Y. Zhou, C. Yang and Y. Li, Nanotechnology, 2007, 18, 2-8.

50 S. Rengaraj, S. Venkataraj, C. W. Tai, Y. Kim, E. Repo and M. Sillanpää, Langmuir, 2011, 27, 5534-5541.

51 M. Chiang, S. Chang, C. Chen, F. Yuan and H. Tuan, J. Phys. Chem. C, 2011, 5, 1592-1599.

52 S. Yang, C. Y. Xu, L. Yang, S. P. Hu and L. Zhen, RSC Adv., 2016, 6, 106671-106675. 